\title{
Preliminary Testing of Hybrid Catalytic-Plasma Reactor for Biodiesel Production Using Modified-Carbon Catalyst
}

\author{
Luqman Buchori, I. Istadi*, P. Purwanto, Anggun Kurniawan, Teuku Irfan Maulana \\ Department of Chemical Engineering, Faculty of Engineering, Diponegoro University \\ Jl. Prof. Soedarto, SH, Kampus Undip Tembalang, Semarang 50275, Indonesia
}

Received: 10 $0^{\text {th }}$ November 2015; Revised: $16^{\text {th }}$ January 2016; Accepted: $16^{\text {th }}$ January 2016

\section{Abstract}

Preliminary testing of hybrid catalytic-plasma reactor for biodiesel production through transesterification of soybean oil with methanol over modified-carbon catalyst was investigated. This research focused on synergetic roles of non-thermal plasma and catalysis in the transesterification process. The amount of modified-carbon catalyst with grain size of $1.75 \mathrm{~mm}$ was placed into fixed tubular reactor within discharge zone. The discharge zone of the hybrid catalytic-plasma reactor was defined in the volume area between high voltage and ground electrodes. Weight Hourly Space Velocity (WHSV) of $1.85 \mathrm{~h}^{-1}$ of reactant feed was studied at reaction temperature of $65{ }^{\circ} \mathrm{C}$ and at ambient pressure. The modified-carbon catalyst was prepared by impregnation of active carbon within $\mathrm{H}_{2} \mathrm{SO}_{4}$ solution followed by drying at $100^{\circ} \mathrm{C}$ for overnight and calcining at $300^{\circ} \mathrm{C}$ for $3 \mathrm{~h}$. It was found that biodiesel yield obtained using the hybrid catalytic-plasma reactor was $92.39 \%$ and $73.91 \%$ when using active carbon and modified-carbon catalysts, respectively better than without plasma. Therefore, there were synergetic effects of non-thermal plasma and catalysis roles for driving the transesterification process. Copyright (C) 2016 BCREC GROUP. All rights reserved

Keywords: biodiesel; modified-carbon catalyst; hybrid catalytic-plasma reactor; transesterification

How to Cite: Buchori, L., Istadi, I., Purwanto, P., Kurniawan, A., Maulana, T.I. (2016). Preliminary Testing of Hybrid Catalytic-Plasma Reactor for Biodiesel Production Using Modified-Carbon Catalyst. Bulletin of Chemical Reaction Engineering \& Catalysis, 11 (1): 59-65. (doi:10.9767/bcrec.11.1.416.5965)

Permalink/DOI: http://dx.doi.org/10.9767/bcrec.11.1.416.59-65

\section{Introduction}

Basically, energy is a basic requirement of a country in supporting the development of industries and transportations.. An increased country's population and industry required more energy usage so that energy demand increased. Commonly, main sources of energy are

* Corresponding Author.

E-mail: istadi@che.undip.ac.id (I. Istadi),

luqman.buchori@che.undip.ac.id (L. Buchori)

Telp./Fax.: +62247460058 / +622476480675 fossil fuels, i.e. petroleum, natural gas and coal [1], but this source of energy is limited. If these energy sources were used continuously, there will be energy scarcity. Biodiesel as a source of renewable and environmentally benign has now become a highlighted topic as the policy of every country. Biodiesel production has become an area of intense research because of the increased interest to find sources of new alternative energy for transportation fuels [1].

Many methods have been developed for the production of biodiesel. The most widely used 
method for biodiesel production in industrial scale is conventional method using homogeneous and heterogeneous catalysts, either acid or base catalysts [2-9]. However, the conventional catalytic reaction technology is considered inefficient because of the length of time the reaction and batch time and some separation processes. Many previous researchers developed enzymatic transesterification process in the synthesis of biodiesel [10-13]. The enzymatic transesterification process has several advantages including the easier product separation process, does not require waste treatment, can easily recover glycerol and high selectivity and activity $[10,14]$. However, the drawback of this method are long residence time, requires a catalyst concentration in large quantities and high price of enzyme [14, 15].

Advanced methods developed in the production of biodiesel were supercritical [16, 17], microwave [18, 19], ultrasonic [20, 21], and plasma technology $[22,23]$ methods. Some researchers studied the effect of the use of the reactor type to biodiesel yield as well as the process efficiency in biodiesel production [21, 2426]. Olivares-Carrillo and Quesada-Medina [27] studied transesterification process of refined soybean oil in a batch reactor using supercritical methanol. The maximum conversion achieved was $84 \%$ at a temperature of $325{ }^{\circ} \mathrm{C}$ and reactor pressure of $35 \mathrm{MPa}$ with a total time of 60 minutes. However, use of this supercritical batch reactor has several drawbacks including requiring high temperature and pressure so that less economical. On the other hand, the use of fixed bed reactors for the production of biodiesel is inefficient because it takes a relatively long time is about 20 hours in order to achieve a conversion of $95 \%$ at a temperature of $250{ }^{\circ} \mathrm{C}$ and a pressure of $1 \mathrm{~atm}$ [28].

Maddikeri et al. [21] investigated effect of using ultrasonic wave radiation on the performance of the reactor in the biodiesel production. The maximum yield of biodiesel that can be achieved was $90 \%$ at a temperature of $40{ }^{\circ} \mathrm{C}$ and at atmospheric pressure. Meanwhile, the use of ultrasound in the transesterification of waste cooking oil by Babajide et al. [20] obtain a conversion of $>90 \%$ at temperature of $30{ }^{\circ} \mathrm{C}$ and a pressure of $1 \mathrm{~atm}$. However, weakness of ultrasound technology on the performance of this reactor are requiring quite long reaction time of about 30 minutes, the formation of glycerol as a byproduct and requiring a homogeneous alkaline catalyst. In other researches, microwave technology for producing biodiesel has been studied by Liu et al. [29]. More than 90\% conversion of the transesterification was achieved at $80^{\circ} \mathrm{C}$ and at atmospheric pressure. However, the time required to reach this conversion is very long which is about 7 hours.

In more advanced technology, the use of plasma reactors on biodiesel synthesis was considered very promising due to only very short reaction time. Study on high energetic electrons as a catalyst in biodiesel synthesis from vegetable oils has been carried out by Istadi et al. [22]. This system could produce fatty acid methyl ester with the yield of $75.65 \%$ within 120 seconds over high voltage plasma reactor (DC $10 \mathrm{kV}$ high voltage, dielectric barrier discharge). In this plasma technology, high energetic electrons can affect the reaction through electron collisions during the chemical reaction. These high energetic electrons have role on interfering the electrons pairs in covalent bonding that would be excited or dissociated even ionized. However, use of this electro-catalysis system in biodiesel production has weaknesses mainly due to lower product selectivity compared to conventional catalysis reaction technology $[22,30]$. Therefore, the study of improving the selectivity of reaction within plasma reactor for the production of biodiesel needs to be developed.

In this paper, the hybrid catalytic-plasma reactor was developed in order to improve the selectivity to biodiesel (especially fatty acid methyl esters). The high voltage plasma was applied on the catalytic reaction within the discharge zone. The plasma was expected to affect the cracking of covalent bonding during chemical synthesis catalytically.

\section{Experimental Methods}

\subsection{Materials}

Commercial soybean oil was purchased from local market (Happy Soya Oil) to be used as raw material. Methanol (Merck, 99.9\%) was used as reactant. Active carbon was purchased from local market. The modified-carbon catalyst was prepared by impregnation of active carbon within $\mathrm{H}_{2} \mathrm{SO}_{4}$ solution $0.1 \mathrm{~N}$ followed by drying at $100{ }^{\circ} \mathrm{C}$ for overnight in an oven (Memmert) and calcinations at $300{ }^{\circ} \mathrm{C}$ for $3 \mathrm{~h}$ in a box furnace. Active carbon has surface area of $170 \mathrm{~m}^{2} / \mathrm{gram}$, while modified carbon has 241 $\mathrm{m}^{2} /$ gram.

\subsection{Hybrid catalytic-plasma reactor sys- tem}

Synergetic catalytic-plasma reaction system to produce biodiesel was performed in a hybrid catalytic-plasma reactor (Dielectric-Barrier 
Discharge, DBD). The reactor was equipped with electric furnace and temperature control to adjust the reactor temperature. Catalyst with the diameter of $1.75 \mathrm{~mm}$ was placed into tubular reactor within discharge zone. High voltage power supply with power up to 330 Watt $(7 \mathrm{kV} \mathrm{DC})$ is used to provide high voltage on the reactor. High Voltage Probe (SEW PD28) and multimeter (Sanwa) is used to measure the voltage during the reaction process. High voltage electrode flows high energetic electrons toward ground electrode through the glass barrier. The energetic electrons collide to the liquid reactants that flow on the surface of catalyst grains. The glass barrier was purposed to distribute the electrons from high voltage electrode toward ground electrode.

\subsection{Procedures}

Reactants consisting of soybean oil and methanol with a molar ratio of 15:1 (methanol/oil) flowed into the mixing tank and stirred evenly. The mixture of methanol and oil was then flowed into the plasma reactor with Weight Hourly Space Velocity (WHSV) of 1.85 $\mathrm{h}^{-1}$. Thus, the reactor was heated up to $65^{\circ} \mathrm{C}$ at atmospheric pressure, which in turn a $7 \mathrm{kV}$ DC high voltage was applied on the discharge zone through the electrodes. In this reactor, high voltage electrode connected to high voltage probe while the ground electrode was connected to earth ground. Distance between both electrodes was $1.5 \mathrm{~cm}$. Effect of catalyst type was studied by varying the catalyst type, i.e. active carbon, modified carbon, and glass grain. Effect of the plasma was investigated by conducting transesterification process with and without plasma on the modified carbon catalyst. Furthermore, the reaction products were analyzed by Gas Chromotography-Mass Spectrometry (GC-MS) (QP2010S SHIMADZU, DB-1 column) to identify the content of fatty acid methyl ester (FAME) and biodiesel.

Yields of FAME and biodiesel can be calculated using Equations (1) and (2).

$$
\text { Yield }_{\text {FAME }}=\frac{\% F A M E G C \text { area } x \rho_{\text {biodiesel }} x V_{\text {biodiesel }}}{\text { weight of soybeanoil feed }} x 100 \%
$$

$$
\text { Yield }_{\text {Biodiesel }}=\frac{\rho_{\text {biodiesel }} x V_{\text {biodiesel }}}{\text { weight of soybeanoil feed }} x 100 \%
$$

\subsection{Catalyst and biodiesel characteriza- tions}

In order to determine composition of resulted product, the biodiesel product was ana- lyzed by GC-MS (QP2010S SHIMADZU, DB-1 column). The samples were analyzed with an oven temperature of $50{ }^{\circ} \mathrm{C}$ (5 minutes) and raised $10^{\circ} \mathrm{C} /$ minute up to a temperature of 260 ${ }^{\circ} \mathrm{C}$ and held for 33 minutes.

The crystal structure of the catalysts (active carbon and modified-carbon) before and after used were analyzed by XRD (X-Ray Diffraction, Shimadzu XRD-7000) with $\mathrm{Cu}-\mathrm{Ka}$ radiation $(k$ $=1.54 \AA$ ) operated at $30 \mathrm{~mA}$ and $30 \mathrm{kV}$. The sample was scanned at the boundary between $10^{\circ}$ to $90^{\circ}$ with a scanning speed of $2 \%$ menit. Furthermore, diffractogram / peak was compared to the data from JCPDS (Joint Committee of Diffraction Data) library to determine the compounds contained in the catalyst.

Change of surface area of the catalyst (active carbon and modified-carbon) before and after used in the transesterification process were analyzed by BET (Brunauer-EmmettTeller) method. Surface area measurements were conducted using Nitrogen adsorptiondesorption at $77 \mathrm{~K}$ (Quantachrome equipment). The samples were out gassed out for $5 \mathrm{~h}$ at 300 ${ }^{\circ} \mathrm{C}(573 \mathrm{~K})$ under vacuum pressure $\left(6.58 \times 10^{-5}\right.$ Torr) prior to the sorption measurements.

\section{Results and Discussion}

\subsection{Roles of plasma reactor}

The use of hybrid catalytic-plasma reactor is interesting due to expectation of assisting the catalysis process by high energetic electrons in molecular level. There is synergetic effect between plasma system (containing high energetic electrons, excited atoms, and neutral particles) with heterogeneous surface catalysis roles. The synergism is possible in activating the reactants in the discharge zone or even to assist cracking the covalent bonding of reactants before the main reaction takes place and finally giving a positive effect on the reaction mechanism and rate [30, 31].

The most interesting in hybrid catalyticplasma system is shorter reaction time so that the total reaction time can be minimized. This type of reactor is also potential for reactions of organic and inorganic chemicals because of its non-equilibrium. The hybrid catalytic - Dielectric Barrier Discharge (DBD) plasma reactor is very promising because of high conversion rates, shorter reaction time, and more efficient power requirement [31]. Meanwhile, the catalyst placed in the discharge zone is an alternative solution to improve the selectivity of reaction to produce biodiesel [32]. The use of hybrid catalytic-plasma system in the synthesis of biodiesel is expected to generate significant syner- 
gies between the plasma and the catalysis in influencing the reactions condition and biodiesel selectivity.

\subsection{Effect of plasma treatment on trans- esterification reaction performance}

Effect of plasma treatment on catalytic transesterifcation reaction of methanol and triglyceride to produce biodiesel was described in Table 1. The reaction performance of biodiesel production was presented as yields of FAME and biodiesel. The yields of biodiesel and FAME were calculated using Equations (1) and (2). From Table 1, it is shown that plasma treatment has significant effect on the synthesis of biodiesel over the hybrid catalytic-plasma reactor. This is true because the yield of transesterification reaction involving plasma treatment is better than that without plasma treatment. This phenomenon is caused by the ability of plasma to influence the reaction through collisions of high energetic electrons from electrode and electrons pairs from the chemical bonding. During the plasma process, the energetic electrons interfere the electrons pairs of covalent bonding of the reactants that would be excited or dissociated so that the activation energy required during surface reaction in the catalyst surface could be reduced [22, 23, 31]. Without the role of plasma, the time of reaction required to form FAME would be longer as studied by Ketchong et al. [24]. They studied transesterification process to produce FAME using limestone as a catalyst in a fixed bed reactor (without plasma) with molar ratio of methanol to oil is ranged 15-30. In the current research, the residence time needed during transesterifcation process when assisted by plasma system was about 5 minutes. When using modified carbon as catalyst but no plasma treatment, it did not produce FAME which may be due to larger molar ratio of reactants and longer time of reaction was required [24, 28].

This research used active carbon, modified carbon as catalyst in plasma reactor as well as using glass bead for plasma process without catalyst. The use of catalysts in hybrid catalyticplasma reactor system was aimed to improve the selectivity and to control the reaction mechanism towards the desired products (FAME/biodiesel). The synergetic effect of catalytic-plasma was also occurred when plasma assists the catalytic process in the catalyst surface. The catalyst placed in the discharge zone also increased contact area and contact time between high energetic electron and reactants molecules. The phenomenon probably triggers excitation of electrons pairs of reactants molecules from the ground state to the outer stationary states. This excitation will lower binding energy of the reactants so that termination of the bonding chain becomes easier [32-35]. In the hybrid catalytic-plasma process, active species (high energetic electrons, metastable compounds, free radicals) are not only formed around the plasma discharge zone, but also in pores of the catalyst due to direct contact between the plasma and the catalyst [36]. The formation of active species, such as free radicals and metastable compound, would increase the likelihood of a reaction between the adsorbed reactants on the surface of the catalyst with either active species formed in the discharge chamber and the pores of the catalyst which in turn forms FAME and biodiesel. This leads to high yield of FAME and biodiesel on the use of activated carbon as the catalyst [36].

The opposite result occurred when using the plasma reactor with modified carbon as the catalyst in which the transesterification process produces FAME with lower yield than that with active carbon as catalyst. This phenomenon is explained by BET surface area analysis that modified carbon (surface area: $241 \mathrm{~m}^{2} /$ gram) has surface area greater than the active carbon (surface area: $170 \mathrm{~m}^{2} / \mathrm{gram}$ ). However, the yield of FAME produced by the modified carbon was lower than that when using the active carbon. This may be due to blocking of catalyst pore during sulfonation process performed by sulfur

Table 1. Yield of FAME and biodiesel at various reactor configurations (plasma treated or nonplasma treated)

\begin{tabular}{lcc}
\hline \multicolumn{1}{c}{ Reactor Configurations } & Yield of FAME (\%) & Yield of Biodiesel (\%) \\
\hline Plasma + active carbon & 68.31 & 92.39 \\
Plasma + modified carbon & 17.01 & 73.91 \\
Non Plasma + modified carbon & 00.00 & 00.00 \\
Plasma + glass bead (without cata- & 46.20 & 46.20 \\
lyst) & & \\
\hline
\end{tabular}




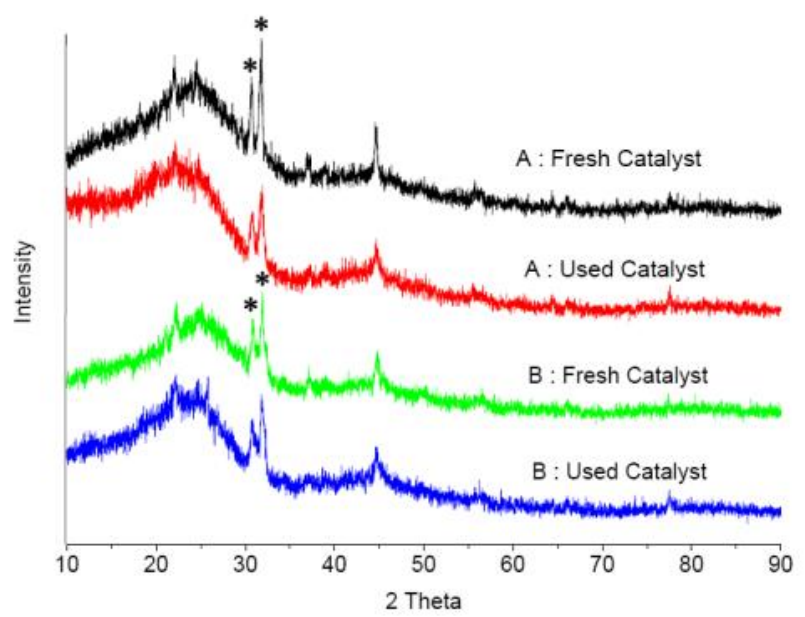

Figure 1. Results of XRD analysis: $A=$ Active Carbon; B = Modified Carbon

component and inhibit adsorption of reactants to the active site of the catalyst [36-39]. The abundance of sulfur atoms attached to the surface of the catalyst is depicted in the XRD result as shown in Figure 1.

Figure 1 indicates that both active carbon and modified carbon showed the similar trend. Sulfonation not alter the crystal structure of the active carbon only causes a decrease in the intensity of the peak $2 \theta\left(30.69^{\circ}\right.$ and $\left.31.75^{\circ}\right)$. The decreased peak intensities were due to attachment of abundant $-\mathrm{SO}_{3} \mathrm{H}$ groups [40].

Meanwhile, when the plasma reactor was filled with glass bead, means without catalyst, the plasma did not give significant effect on the catalysis process. Therefore, without catalyst within plasma discharge zone, the transesterification process was occurred with low selectivity to FAME. In this reactor type, the biodiesel yield was lower than the reactor system which contains the active carbon or the modified carbon as catalyst. This phenomenon is also explained by the formation of various compounds rather than FAME (alcohol, aldehydes, carboxylic acids, alkynes and eicosanoids) [22]. The absence of catalyst role caused the uncontrollable reaction mechanisms so that the cracking the reactant bond chain (methanol and oil) becomes undesirable [41].

\section{Conclusions}

In the hybrid catalytic-plasma reactor system, the plasma and the catalysis gave synergetic effect on driving the transesterification reactions to produce FAME or biodiesel. The use of catalyst in hybrid catalytic-plasma reactor system was able to improve the selectivity and to control the reaction mechanism towards the de- sired products (FAME/biodiesel). The synergetic effect of catalytic-plasma was also occurred when the plasma assisted the catalysis process in the catalyst surface. The absence of catalyst role caused the uncontrollable reaction mechanisms so that the cracking the reactant bond chain (methanol and oil) becomes undesirable. However, much improvement and modification will be done in future work including plasma reactor configuration, pellet size and shape, catalyst-plasma roles in reaction, etc.

\section{Acknowledgments}

The authors would like to express their sincere gratitude's to the Directorate General of Higher Education (DIKTI) for the financial support received under the research project of Hibah Kompetensi Year 2015 through DIPA Undip by contract no.: 147-03/UN7.5.1/ $\mathrm{PG} / 2015$.

\section{References}

[1] Juan, J.C., Kartika, D.A., Wu, T.Y., Hin, T.Y.Y. (2011). Biodiesel production from jatropha oil by catalytic and non-catalytic approaches: An overview, Bioresour. Technol., 102(2): 452-460.

[2] Zheng, S., Kates, M., Dubé, M.A., McLean, D.D. (2006). Acid-catalyzed production of biodiesel from waste frying oil, Biomass and Bioenergy, 30(3): 267-272.

[3] Bhatti, H., Hanif, M., Qasim, M. (2008). Biodiesel production from waste tallow, Fuel, 87(13-14): 2961-2966.

[4] Issariyakul, T., Dalai, A.K. (2010). Biodiesel production from greenseed canola oil, Energy and Fuels, 24(7): 4652-4658.

[5] Rashid, U., Anwar, F., Moser, B.R., Ashraf, S. (2008). Production of sunflower oil methyl esters by optimized alkali-catalyzed methanolysis, Biomass and Bioenergy, 32(12): 1202-1205.

[6] Melero, J.A., Bautista, L.F., Morales, G., Iglesias, J., Sánchez-Vázquez, R. (2010). Biodiesel production from crude palm oil using sulfonic acid-modified mesostructured catalysts, Chem. Eng. J., 161(3): 323-331.

[7] Yan, F., Yuan, Z., Lu, P., Luo, W., Yang, L. Deng, L. (2011). Fe-Zn double-metal cyanide complexes catalyzed biodiesel production from high-acid-value oil, Renew. Energy, 36(7): 2026-2031.

[8] Liu, X., Xiong, X., Liu, C., Liu, D., Wu, A., $\mathrm{Hu}$, Q., Liu, C. (2010). Preparation of biodiesel by transesterification of rapeseed oil 
with methanol using solid base catalyst calcined $\mathrm{K}_{2} \mathrm{CO}_{3} / \mathrm{Al}_{2} \mathrm{O}_{3}$, J. Am. Oil Chem. Soc., 87(7): 817-823.

[9] Sun, H., Ding, Y., Duan, J., Zhang, Q., Wang, Z., Lou, H., Zheng, X. (2010). Transesterification of sunflower oil to biodiesel on $\mathrm{ZrO}_{2}$ supported $\mathrm{La}_{2} \mathrm{O}_{3}$ catalyst, Bioresour. Technol., 101(3): 953-958.

[10] Jegannathan, K.R., Abang, S., Poncelet, D., Chan, E.S., Ravindra, P. (2008). Production of biodiesel using immobilized lipase-a critical review, Crit. Rev. Biotechnol., 28(4): 253-264.

[11] Yan, J., Zheng, X., Li, S. (2014). A novel and robust recombinant Pichia pastoris yeast whole cell biocatalyst with intracellular overexpression of a Thermomyces lanuginosus lipase: Preparation, characterization and application in biodiesel production, Bioresour. Technol., 151: 43-48.

[12] Kumari, V., Shah, S., Gupta, M.N. (2007). Preparation of biodiesel by lipase-catalyzed transesterification of high free fatty acid containing oil from Madhuca indica, Energy and Fuels, 21(12): 368-372.

[13] Christopher, L.P., Kumar, H., Zambare, V.P. (2014). Enzymatic biodiesel: Challenges and opportunities, Appl. Energy, 119: 497-520.

[14] Bajaj, A., Lohan, P., Jha, P.N., Mehrotra, R. (2010). Biodiesel production through lipase catalyzed transesterification: An overview, $J$. Mol. Catal. B: Enzym., 62(1): 9-14.

[15] Hama, S., Kondo, A. (2013). Enzymatic biodiesel production: An overview of potential feedstocks and process development, Bioresour. Technol., 135: 386-395.

[16] Micic, R.D., Tomić, M.D., Kiss, F.E., NikolićDjorić, E.B., Simikić, M. (2014). Influence of reaction conditions and type of alcohol on biodiesel yields and process economics of supercritical transesterification, Energy Convers. Manag., 86: 717-726.

[17] Yin, J.Z., Xiao, M., Song, J.B. (2008). Biodiesel from soybean oil in supercritical methanol with co-solvent, Energy Convers. Manag., 49(5): 908-912.

[18] Chen, K.S., Lin, Y.C., Hsu, K.H., Wang, H.K. (2012). Improving biodiesel yields from waste cooking oil by using sodium methoxide and a microwave heating system, Energy, 38(1): 151-156.

[19] Encinar, J.M., González, J.F., Martínez, G., Sánchez, N., Pardal, A. (2012). Soybean oil transesterification by the use of a microwave flow system, Fuel, 95: 386-393.

[20] Babajide, O., Petrik, L., Amigun, B., Ameer, F. (2010). Low-cost feedstock conversion to biodiesel via ultrasound technology, Energies, 3(10): 1691-1703.
[21] Maddikeri, G.L., Pandit, A.B., Gogate, P.R. (2013). Ultrasound assisted interesterification of waste cooking oil and methyl acetate for biodiesel and triacetin production, Fuel Process. Technol., 116: 241-249.

[22] Istadi, I., Yudhistira, A.D., Anggoro, D.D., Buchori, L. (2014). Electro-Catalysis System for Biodiesel Synthesis from Palm Oil over Dielectric-Barrier Discharge Plasma Reactor, Bull. Chem. React. Eng. Catal., 9(2): 111-120.(doi:10.9767/bcrec.9.2.6090.111-120)

[23] Lawson, J.A., Baosman, A.A. (2010). Method of Electro-Catalytic Reaction to Produce Mono Alkyl Esters for Renewable Biodiesel, US Patent 7,722,755 B2 (25 May 2010).

[24] Ketcong, A., Meechan, W., Naree, T., Seneevong, I., Winitsorn, A., Butnark, S., Ngamcharussrivichai, C. (2014). Production of fatty acid methyl esters over a limestonederived heterogeneous catalyst in a fixedbed reactor, J. Ind. Eng. Chem., 20(4): 16651671.

[25] Wali, W.A., Al-Shamma', A.A.I., Hassan, K.H., Cullen, J.D. (2012). Online geneticANFIS temperature control for advanced microwave biodiesel reactor, J. Process Control, 22(7): 1256-1272.

[26] Ren, Y., He, B., Yan, F., Wang, H., Cheng, Y., Lin, L., Feng, Y., Li, J. (2012). Continuous biodiesel production in a fixed bed reactor packed with anion-exchange resin as heterogeneous catalyst, Bioresour. Technol., 113: 19-22.

[27] Olivares-Carrillo, P., Quesada-Medina, J. (2012). Thermal decomposition of fatty acid chains during the supercritical methanol transesterification of soybean oil to biodiesel, J. Supercrit. Fluids, 72: 52-58.

[28] Furuta, S., Matsuhashi, H., Arata, K. (2006). Biodiesel fuel production with solid amorphous-zirconia catalysis in fixed bed reactor, Biomass and Bioenergy, 30(10): 870-873.

[29] Liu, W., Yin, P., Liu, X., Chen, W., Chen, H., Liu, C., Qu, R., Xu, Q. (2013). Microwave assisted esterification of free fatty acid over a heterogeneous catalyst for biodiesel production, Energy Convers. Manag., 76: 1009-1014

[30] Fridman, A. (2008). Plasma Chemistry, New York, United States of America: Cambridge University Press.

[31] Istadi, I., Amin, N.A.S. (2006). Cogeneration of synthesis gas and $\mathrm{C}_{2+}$ hydrocarbons from methane and carbon dioxide in a hybrid catalytic-plasma reactor: A review, Fuel, 85(5-6): 577-592.

[32] Kim, S.S., Lee, H., Na, B.K., Song, H.K. (2004). Plasma-assisted reduction of supported metal catalyst using atmospheric di- 
electric-barrier discharge, Catal. Today, 89(12): $193-200$.

[33] Pietruszka, B., Heintze, M. (2004). Methane conversion at low temperature: the combined application of catalysis and non-equilibrium plasma, Catal. Today, 90(1-2): 151-158.

[34] Heintze, M., Pietruszka, B. (2004). Plasma catalytic conversion of methane into syngas: The combined effect of discharge activation and catalysis, Catal. Today, 89(1-2): 21-25.

[35] Liu, C., Mallinson, R., Lobban, L. (1999). Comparative investigations on plasma catalytic methane conversion to higher hydrocarbons over zeolites, Appl. Catal. A: Gen., 178(1): 17-27.

[36] Zhu, X., Gao, X., Qin, R., Zeng, Y., Qu, R., Zheng, C. (2015). Plasma-catalytic removal of formaldehyde over $\mathrm{Cu}$-Ce catalysts in a dielectric barrier discharge reactor, Appl. Catal. B: Environ., 170-171: 293-300.

[37] Konwar, L.J., Boro, J., Deka, D. (20104). Review on latest developments in biodiesel production using carbon-based catalysts, Renew. Sustain. Energy Rev., 29: 546-564.
[38] Shu, Q., Zhang, Q., Xu, G., Nawaz, Z., Wang, D., Wang, J. (2009). Synthesis of biodiesel from cottonseed oil and methanol using a carbon-based solid acid catalyst, Fuel Process. Technol., 90(7-8): 1002-1008.

[39] Huu, T.P., Gil, S., Da Costa, P., GiroirFendler, A., Khacef, A. (2015). Plasmacatalytic hybrid reactor: Application to methane removal, Catal. Today, 257: 86-92.

[40] Konwar, L.J., Das, R., Thakur, A.J., Salminen, E., Mäki-Arvela, P., Kumar, N., Mikkola, J.P., Deka, D. (2014). Biodiesel production from acid oils using sulfonated carbon catalyst catalystderived from oil-cake waste, J. Molec. Catal. A: Chem., 388-389: 167-176.

[41] Rahimpour, M.R., Jahanmiri, A., Mohamadzadeh Shirazi, M., Hooshmand, N., Taghvaei, H. (2013). Combination of non-thermal plasma and heterogeneous catalysis for methane and hexadecane co-cracking: Effect of voltage and catalyst configuration, Chem. Eng. J., 219: 245-253.

Selected and Revised Papers from The $2^{\text {nd }}$ International Conference on Chemical and Material Engineering 2015 (ICCME 2015) (29-20 September, 2015, Semarang, Indonesia)

(http://econference.undip.ac.id/index.php/iccme/2015) after Peer-reviewed by ICCME 2015 and BCREC Reviewers 